\title{
Role of tailored surface of activated carbon for adsorption of ionic liquids for environmental remediation
}

\author{
S. Hassan - T. Yasin
}

Received: 29 April 2014/Revised: 2 August 2014/Accepted: 23 September 2014/Published online: 28 October 2014

(C) Islamic Azad University (IAU) 2014

\begin{abstract}
The surface of activated carbon (AC) was oxidized using different oxidizing agents (nitric acid and sodium hypochlorite). This modified AC (mAC) was used for the adsorption of ionic liquids (ILs). These mACs were characterized before and after adsorption of ILs using different techniques. The surface area of AC decreased after oxidation, but total acidity increased as compared to untreated AC. The $\mathrm{pH}$ of point zero charge of ACs was also decreased after oxidation. The role of adsorbents and its interaction with ILs have been investigated using batch adsorption experiments. Both the alkyl chain length and cation type of ILs affected their adsorption onto ACs; long alkyl chain showed higher adsorption. The $\mathrm{pH}$ study showed higher adsorption at higher $\mathrm{pH}$ as compared to lower $\mathrm{pH}$ value. The pseudo-second-order model was best fitted to the kinetic adsorption data, and Langmuir isotherm model was best fitted on isotherm data. The overall adsorption process was controlled by intra-particle diffusion and external mass transfer. The adsorption results obtained in this study showed comparably higher value with published literature.
\end{abstract}

Keywords Adsorption properties - Aqueous solution · Isotherms models $\cdot$ Surface functional groups

\section{Introduction}

The main aim of modification (oxidation) of activated carbon (AC) was to obtain hydrophilic structure at its

S. Hassan $(\bowtie) \cdot$ T. Yasin

Pakistan Institute of Engineering and Applied Sciences (PIEAS),

P. O. Nilore, Islamabad 45650, Pakistan

e-mail: hassan.chem01@gmail.com surface with large number of oxygen-containing functional groups. The oxidized surface of AC showed variety of oxygen-containing groups such as phenols, carboxylic acid, aldehyde, and ketone having ion exchange properties. This can be used in the preparation of carbon-supported supercapacitor by exchanging with cationic ionic liquids as electrolyte, resulting in high-performance supercapacitor. For other carbon-based supercapacitor, modification of AC results in significant change in capacitance for ionic liquids (Boehm 1994; Conway 1999).

Activated carbon is mostly used for the adsorption of pollutants from aqueous solution (Roosta et al. 2014b, c). To enhance its adsorption property, the surface of $\mathrm{AC}$ is modified by chemical method such as oxidation by using various oxidizing agents such as concentrated sulfuric or nitric acid, sodium hypochlorite $(\mathrm{NaOCl})$, bichromate, permanganate, hydrogen peroxide, and ozone (Ermolenko et al. 1990; Lisovskii et al. 1997; Pittman et al. 1997).

Among these oxidation treatments, the nitric acid oxidation is widely used to increase the total surface acidity of AC. It is reported that oxidation with nitric acid significantly increased the amount of functional groups including carboxylic acid (Donnet and Ehrburger 1977). In composites system, the modified AC increased the interfacial adhesion forces between the components (Donnet and Bansal 1990; Peebles 1995; Radovic et al. 1997; Park and Kim 2000). But limited work is reported on the use of mAC for the adsorption of ionic liquids.

Ionic liquids have gained significant attention due to wide range of applications, including catalysis, synthesis (Olivier-Bourbigou et al. 2010) and biocatalytic reactions (van Rantwijk and Sheldon 2007), electrochemical (Armand et al. 2009), separation processes (Han and Armstrong 2007; Claudio et al. 2010), supercapacitors (Xu et al. 2010), nanomaterials (Migowski and Dupont 2007) 
and some processes working at industrial scale (Plechkova and Seddon 2008). The ILs are categorized as green solvents in comparison with the other conventional organic solvents. But due to solubility in water, low vapor pressure and stability, they pose a serious threat to the environment and their toxicity have also been reported in literature (Wasserscheid and Welton 2008).

In adsorption process, oxygen-containing functional groups play an important role. Mattson et al. (1969) suggests that donor-acceptor complexes are formed with an interaction between aromatic rings of phenol (acceptors) and carbonyl surface groups (as electron donors) of AC. Other researchers proposed the formation of hydrogen bond between carboxylic groups of $\mathrm{AC}$, and hydroxyl groups of phenol play important role on adsorption of phenol (Franz et al. 2000).

In the present work, we have investigated the role of surface functional groups of $m A C$ for the adsorption of different classes of ILs. The surface of granulated activated carbon was modified with nitric acid $\left(\mathrm{HNO}_{3}\right)$ and $\mathrm{NaOCl}$ to enhance the adsorption capacity of AC for ILs. A commercial microporous granulated $\mathrm{AC}$ was oxidized to obtain adsorbents with different surface properties. The AC was characterized by Boehm titration, and BET and the data at equilibrium adsorption were modeled using Langmuir equations. In order to investigate the impact of the surface chemistry on the ILs adsorption, the adsorption properties of the raw and modified ACs were studied as a function of $\mathrm{pH}$ and concentration and characterized by different techniques before and after adsorption of ILs.

\section{Materials and methods}

\section{Materials}

Concentrated nitric acid, sodium hypochlorite, 1-methylimidazole and chlorooctane, chlorobutane, $\mathrm{Na}_{2} \mathrm{CO}_{3} / \mathrm{NaOH} /$ $\mathrm{NaHCO}_{3}, \mathrm{NaCl}, \mathrm{HNO}_{3}, \mathrm{NaOCl}$ and $\mathrm{HCl}$ were supplied by Sigma-Aldrich, Chemie (Steinheim, Germany). The 1-octylpyridinium bromide $(\mathrm{OPyBr})$ was taken from Solvionic company, France. The commercial grade AC was purchased from Chinese company (China).

Synthesis of ionic liquids

1-Methyl-3-butylimidazolium chloride (BMImCl) and 1-methyl-3-octylimidazolium chloride $(\mathrm{OMImCl})$ were manufactured from 1-methylimidazole and chlorooctane, and chlorobutane in our laboratory using conventional synthesis methods. The reactions were conducted in glass reactor at room temperature using stirring in solvent-free environment for $24 \mathrm{~h}$. Products were purified by successive washing in ether, cyclohexane and ethyl acetate and vacuum dried till constant weight. The final product was placed in closed containers and stored in desiccator.

The sizes (length, width and height) of the three ionic liquids cations octylpyridinium: $\mathrm{OPy}^{+}, 1$-methyl-3-octylimidazolium: $\mathrm{OMIm}^{+}$and 1-butyl 3-methylimidazolium: $\mathrm{BMIm}^{+}$were estimated using 'Chemsketch 3D Viewer' assuming that shape of molecule was a parallelepiped. The estimated sizes of all cation of ILs were as follows: for $\mathrm{OPyBr}(14.3 \times 5.1 \times 1.8 \AA)$, for $\mathrm{OMImCl}(14.2 \times 5.3 \times$ $1.8 \AA)$ and for $\mathrm{BMImCl}(9.2 \times 5.4 \times 1.9 \AA)$. It can be seen from these sizes that the alkyl chain length in $\mathrm{OPyBr}$ and $\mathrm{OMImBr}$ is quite similar and larger as compared to BMImBr ILs.

\section{Adsorbents}

Before modification, the $\mathrm{AC}$ was dried in oven at $110^{\circ} \mathrm{C}$ in order to remove moisture from AC. Then, raw AC (RAC) was modified by two ways. In first case, the bleaching of $\mathrm{AC}$ was performed by slow addition of $400 \mathrm{ml}$ of $10 \%$ $\mathrm{NaOCl}$ solution into $150 \mathrm{~g}$ of RAC, dispersed in water. The mixture was stirred for $24 \mathrm{~h}$ at room temperature. After stirring, the suspension was washed with $\mathrm{HCl}$ and distilled water till the neutral $\mathrm{pH}$ of solution was achieved. This AC was called as bleached activated carbon (BAC). In second case, the RAC was treated with $\mathrm{HNO}_{3}$. Approximately $90 \mathrm{~g}$ of RAC was boiled in $5 \mathrm{M} \mathrm{HNO}_{3}$ for $5 \mathrm{~h}$ in threenecked round bottom flask. Then, AC was filtered and washed with distilled water till the neutral $\mathrm{pH}$. This $\mathrm{AC}$ was called acidified AC (AAC). Then, both the ACs were filtered and dried in oven for $24 \mathrm{~h}$ at $120^{\circ} \mathrm{C}$ and store in air-tight container.

$\mathrm{N}_{2}$ adsorption-desorption at $77 \mathrm{~K}$

$\mathrm{N}_{2}$ adsorption-desorption isotherms of the AC were measured at automatic adsorption instrument (ASAP 2000, Micromeritics). Before measurements, the carbon samples were degassed for $12 \mathrm{~h}$ at $300{ }^{\circ} \mathrm{C}$ under vacuum. The surface area of the nitrogen molecule was assumed to be $0.162 \mathrm{~nm}^{2}$ by Langmuir model. The total pore volume was assessed as the liquid volume of adsorbate $\left(\mathrm{N}_{2}\right)$, which was adsorbed at a comparative pressure of 0.99 .

Boehm method and $\mathrm{pH}_{\mathrm{PZC}}$ determination

The amount of surface functional groups such as lactone, carboxylic, quinone/carbonyl, phenol groups was measured by Boehm titrations method (Boehm 1994). In each experiment, $\mathrm{AC}(50 \mathrm{mg})$ was added in a closed flask containing $150 \mathrm{ml}(0.1 \mathrm{M})$ solution of reactant $\left(\mathrm{Na}_{2} \mathrm{CO}_{3} /\right.$ $\mathrm{NaOH} / \mathrm{NaHCO}_{3}$ ). The mixtures were stirred at $150 \mathrm{rpm}$, at 
$25^{\circ} \mathrm{C}$. After $48 \mathrm{~h}$ of stirring, the solution was filtered using $0.45 \mu \mathrm{m}$ membrane filters. The titrations of the filtrate were done in order to find out oxygenated group content.

The $\mathrm{pH}$ of the point of zero charge $\left(\mathrm{pH}_{\mathrm{PZC}}\right)$ of raw and modified ACs was found by using $\mathrm{pH}$ drift method (LopezRamon et al. 1999). In this method, $0.15 \mathrm{~g}$ of $\mathrm{AC}$ was added in $50 \mathrm{~mL}$ of $\mathrm{NaCl}(0.01 \mathrm{M})$ solutions. The $\mathrm{pH}$ of the solutions (deoxygenated) was adjusted to successive initial values between 2 and 12. At equilibrium, the final $\mathrm{pH}$ was measured by stirring the solution (suspensions) for $48 \mathrm{~h}$ under $\mathrm{N}_{2}$ atmosphere. Then, the $\mathrm{pH}_{\mathrm{PZC}}$ was determined graphically (from the values for which final $\mathrm{pH}$ was equal to initial $\mathrm{pH})$.

\section{Infrared spectroscopy}

Infrared spectra were recorded using Fourier transform infrared spectroscopy (FT-IR, Nicolet 6700, Thermo Electron Corporation, USA). The ATR mode was used, and the ATR assembly contains diamond crystal. Before analysis, the samples were washed with distilled water and dried under vacuum at $120{ }^{\circ} \mathrm{C}$. The samples were scanned from 4,000 to $500 \mathrm{~cm}^{-1}$ at $4 \mathrm{~cm}^{-1}$ resolution, and averages of 200 scans were reported.

\section{X-ray diffraction analysis}

The X-ray diffraction analyses were carried on BragBrentano X-ray diffractometer with $\mathrm{CuK} \alpha_{1}$ ( $\lambda=1.5418 \AA$ ). The scanning range was $10^{\circ}$ to $80^{\circ}$.

Scanning electron microscopic analysis

The scanning electron microscopy (SEM) of AC was done by using scanning electron microscope from Mira $3 \mathrm{XMU}$, TESCAN, MI2881377Pk. A sputtering coating device was used to coat the SEM specimens with gold to increase the conductivity.

\section{Adsorption study}

The batch adsorption experiments were carried out at room temperature in $100 \mathrm{ml}$ flask containing $\mathrm{AC}(50 \mathrm{mg})$ and ILs $(50 \mathrm{ml})$ at $400 \mathrm{rpm}$. In kinetic experiment, $50 \mathrm{mg}$ of $\mathrm{AC}$ was taken in $50 \mathrm{~mL}$ of IL solution at $\mathrm{pH}$ 7. The initial concentration of ionic liquids in kinetin experiment was kept $1 \mathrm{mmol}^{-1}$. The adsorption isotherms study was carried out at $\mathrm{pH} 9,7$ and 2, and the concentration was varied from 0.2 to $5 \mathrm{mmol}^{-1}$ at room temperature for $48 \mathrm{~h}$. The adsorption of ILs on AC was determined using UV-Visible spectrometry (Varian, Cary50) at $211 \mathrm{~nm}$ for $\mathrm{OMIMCl}$ and $\mathrm{BMIMCl}$ at $260 \mathrm{~nm}$ for $\mathrm{OPyBr}$. The $\mathrm{pH}$ is adjusted using buffer solutions; a solution was prepared by using standard method (Weast 1990).

Data analysis

In order to simulate the adsorption kinetics data, four kinetic models were applied to find out the behavior of adsorption process of ILs onto ACs: the pseudo-first-order, the pseudo-second-order (Ho and McKay 1999), the intraparticle diffusion (Weber and Morris 1963) and the Elovich Models (Chien and Clayton 1980). Pseudo-first-order model was given below:

$\log \left(q_{e}-q_{t}\right)=\log q_{e}-\left(\frac{k}{2.203}\right) t$

where ' $q_{e}$ ' and ' $q_{t}$ ' were the amount of IL adsorbed (mmol/ g) on $\mathrm{AC}$ at equilibrium and at time ' $t$,' respectively, and ' $k$ ' $\left(\min ^{-1}\right)$ was the rate constant of the pseudo-first-order adsorption process.

Pseudo-second-order was expressed as follows:

$\frac{t}{q_{t}}=\frac{1}{k}+\left(\frac{1}{q_{e}}\right) t$

where ' $k$ ' was the rate constant $\left(\mathrm{mmol} \mathrm{g}{ }^{-1} \min ^{-1}\right)$, ' $q_{e}$ ' and ' $q_{t}$ ' (mmol/g) were the aggregates of adsorbed IL at equilibrium and at time ' $t$ ' $(\mathrm{min})$, respectively. $k$ and $q_{e}$ values were determined from the linear regression of ' $t / q_{t}$ ' versus ' $t$ ' obtained by integration of the Eq. (2) data for each IL.

Boyd model has following equation (Kumar et al. 2005)

$B_{t}=-\ln \left[1-\frac{q_{t}}{q_{e}}\right]-0.4977$

where $q_{e}$ and $q_{t}$ were the amounts of IL adsorbed onto adsorbent ( $\left.\mathrm{mg} \mathrm{g}^{-1}\right)$ at equilibrium time $t_{e}$ (hour) and time $t$ (hour), respectively.

The adsorption isotherms of the three ILs on the activated carbons at room temperature were simulated by different models. The equation of most fitted model, Langmuir model, was follows (Moreno-Castilla et al. 1998):

$q_{e}=\frac{q_{\mathrm{maxbC}_{\mathrm{e}}}}{1+b C_{e}}$

where ' $C_{e}$ ' was the adsorption equilibrium concentration of the IL in the solution ( $\mathrm{mmol} / \mathrm{l})$, ' $q_{\max }$ ' was the maximum adsorption capacity $(\mathrm{mmol} / \mathrm{g})$, in order to assist in the comparison of adsorption performance when the monolayer surface is fully covered with IL molecules, and ' $b$ ' was the constant concern with the free energy of adsorption $(1 / \mathrm{mmol})$ that related to the affinity of binding sites. Furthermore, in order to understand whether an adsorption system is favorable or not, the effect of the isotherm shape was studied. Another important parameter, 
RL, called the equilibrium parameter or separation factor was used to determine the adsorption feasibility of adsorbent in a given concentration range by the relation (Sonawane and Shrivastava 2011)

$R_{L}=\frac{1}{1+b C_{0}}$

where ' $\mathrm{CO}$ ' was the initial concentration $(5 \mathrm{mmol} / \mathrm{l})$ of IL and ' $b$ ' was the Langmuir adsorption constant $(1 / \mathrm{mmol})$. There were four possibilities: (1) $R L>1$ for unfavorable adsorption; (2) $0<R L<1$ for favorable adsorption; (3) $R L=0$ for irreversible adsorption; and (4) $R L=1$ for linear adsorption (Ho and McKay 1998).

\section{Results and discussion}

Characterization of the activated carbons

The nitrogen adsorption-desorption isotherms of raw and modified ACs. The surface area and textural properties of the ACs are shown in Table 1. In case of AAC, the difference in micropore volume from RAC was $0.12 \mathrm{~cm}^{3} \mathrm{~g}^{-1}$ and difference in total pore volume was $0.11 \mathrm{~cm}^{3} \mathrm{~g}^{-1}$, and in case of BAC, the difference in microspore volume from RAC was $0.05 \mathrm{~cm}^{3} \mathrm{~g}^{-1}$ and difference in total pore volume was $0.02 \mathrm{~cm}^{3} \mathrm{~g}^{-1}$. This decrease was higher in AAC as compared to $\mathrm{BAC}$ because after $\mathrm{HNO}_{3}$ modification, there was a chance that the surface of the smaller microspores was reacted and blocked by complex functional groups containing mainly carboxylic acids with small amount of phenol, anhydrides and lactones (Kutics and Suzuki 1990; Figueiredo et al. 1999), generated during nitric acid treatment (Donnet and Bansal 1990). In BET measurements of dry ACs sample, these pores were not assessed, despite the small molecular size of nitrogen gas. As there was no particular change in the textural properties of modified sample, this suggested that the change in adsorption capacity was due to change in surface properties only (Shim et al. 2001; Faria et al. 2004). The isotherms given by all ACs were L type isotherms. These results confirm that the $\mathrm{AC}$ was typically microporous in nature and no major change took place in their textural properties. However, the specific surface areas $\left(S_{\mathrm{BET}}\right)$ and microporous volume of $\mathrm{mAC}$ were decreased. These results also show that acidification with $\mathrm{HNO}_{3}$ and $\mathrm{NaOCl}$ was an efficient technique for producing functional groups on the surface. The nitrogen adsorption-desorption isotherms of AAC after adsorption of $\mathrm{OMImCl}$ (with loading $0.65 \mathrm{mmol} / \mathrm{g}$ ), OPyBr (with loading $0.51 \mathrm{mmol} / \mathrm{g}$ ) and $\mathrm{BMImCl}$ (with loading $0.40 \mathrm{mmol} / \mathrm{g}$ ) were also done, and data are shown in Table 1. In BAC adsorbed with OMI$\mathrm{mCl}$, the difference in total pore volume was $0.30 \mathrm{~cm}^{3} \mathrm{~g}^{-1}$ and surface area was reduced to $601 \mathrm{~m}^{2} \mathrm{~g}^{-1}$, whereas in $\mathrm{OPyBr}$ the difference in total pore volume was $0.25 \mathrm{~cm}^{3} \mathrm{~g}^{-1}$ and surface area was reduced to $630 \mathrm{~m}^{2} \mathrm{~g}^{-1}$. Same trend was found in BAC adsorbed with BMImCl. This decrease in surface area and pore volume revealed that the adsorption of ILs occurred both on the surface and in the pores of BAC.

The results of surface functional groups of ACs measured by Boehm titration method are (Boehm 1994) shown in Table 2. When $\mathrm{AC}$ was oxidized by $\mathrm{NaOCl}$ or $\mathrm{HNO}_{3}$, the $\mathrm{pH}$ values decreased due to the increase in concentrations of oxygen-containing surface groups from 0.18 to $\sim 0.56 \mathrm{meq} / \mathrm{g}$ (for $\mathrm{NaOCl}$ ) and $0.18-0.67 \mathrm{meq} / \mathrm{g}$ (for $\mathrm{HNO}_{3}$ ). The value of $\mathrm{pH}_{\mathrm{PZC}}$ slightly decreased for the BAC (from 9.5 to 9.3) but more for AAC (from 9.5 to 9.1). This decrease in pHPZC might be attributed to the higher amount of lactonic groups $(0.02 \mathrm{meq} / \mathrm{g}$ for $\mathrm{BAC}$ and $0.04 \mathrm{meq} / \mathrm{g}$ for $\mathrm{AAC})$ and carbonyl groups (0.50 and $0.51 \mathrm{meq} / \mathrm{g}$ for BAC and AAC, respectively). Hence, it was clear that the chemical nature of surface functionality was significantly changed by acid treatment. The Boehm titrations of AC revealed that RAC had least amount of acidic groups with small amount of phenolic groups and a pronounced basic character $(\mathrm{pHPZC}=9.5)$.

The characteristic FTIR pattern of BAC before and after adsorption of ILs is shown in Fig. 1a. The IR spectrum of BAC shows the presence of following functional groups: The peak centered at $3,420 \mathrm{~cm}^{-1}$ was mainly assigned to $\mathrm{O}-\mathrm{H}$ stretching vibrations, and peak at 2,840 and

Table 1 Textural properties of raw Chinese, BAC and AAC before and after adsorption of ILs onto BAC obtained by $\mathrm{N}_{2}$ adsorption/desorption at $77 \mathrm{~K}$

\begin{tabular}{|c|c|c|c|c|c|}
\hline Carbon samples & BET surface area $\left(\mathrm{m}^{2} \mathrm{~g}^{-1}\right)$ & Total pore volume $\left(\mathrm{cm}^{3} \mathrm{~g}^{-1}\right)$ & Microspore volume $\left(\mathrm{cm}^{3} \mathrm{~g}^{-1}\right)$ & $\mathrm{pH}$ & $\mathrm{pH}_{\mathrm{PZC}}$ \\
\hline RAC & 984 & 0.52 & 0.25 & 8.5 & 9.5 \\
\hline BAC & 880 & 0.50 & 0.20 & 7.10 & 9.30 \\
\hline AAC & 819 & 0.41 & 0.13 & 8.0 & 9.10 \\
\hline $\mathrm{BAC}+\mathrm{OMImCl}$ & 601 & 0.20 & 0.10 & - & - \\
\hline $\mathrm{BAC}+\mathrm{OPyBr}$ & 630 & 0.25 & 0.11 & - & - \\
\hline $\mathrm{BAC}+\mathrm{BMImCl}$ & 750 & 0.40 & 0.15 & - & - \\
\hline
\end{tabular}


Table 2 Boehm titration results and $\mathrm{pH}$ of point of zero charge of RAC, BAC and AAC at room temperature

\begin{tabular}{lllllll}
\hline $\begin{array}{l}\text { Activated } \\
\text { Carbon }\end{array}$ & $\begin{array}{l}\text { Carboxylic group } \\
(\mathrm{meq} / \mathrm{g})\end{array}$ & $\begin{array}{l}\text { Lactone group } \\
(\mathrm{meq} / \mathrm{g})\end{array}$ & $\begin{array}{l}\text { Carbonyl } \\
\text { Groups(meq/g) }\end{array}$ & $\begin{array}{l}\text { Phenol group } \\
(\mathrm{meq} / \mathrm{g})\end{array}$ & $\begin{array}{l}\text { Total acidic groups } \\
(\mathrm{meq} / \mathrm{g})\end{array}$ & $\begin{array}{l}\text { Basic groups } \\
(\mathrm{meq} / \mathrm{g})\end{array}$ \\
\hline RAC & 0.008 & 0 & 0.15 & 0.02 & 0.18 & 0.08 \\
BAC & 0.01 & 0.02 & 0.50 & 0.03 & 0.56 & 0.09 \\
AAC & 0.04 & 0.04 & 0.51 & 0.08 & 0.67 & 0.003 \\
\hline
\end{tabular}

Fig. 1 a FTIR spectra, b XRD spectra and $\mathbf{c}$ SEM images of BAC before and after adsorption of ILs

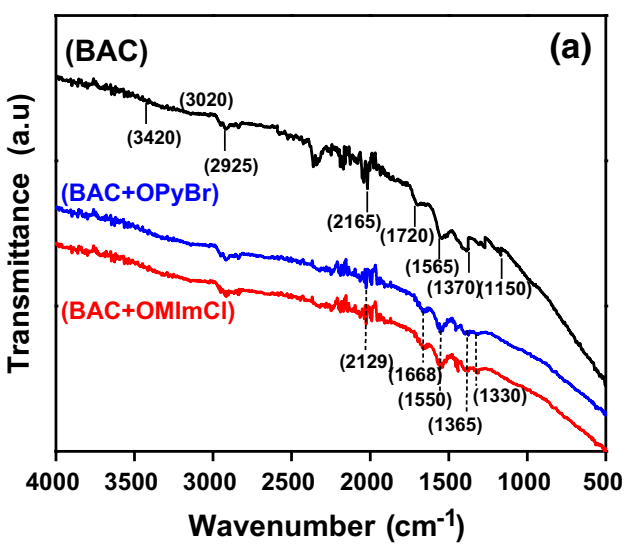

(C)

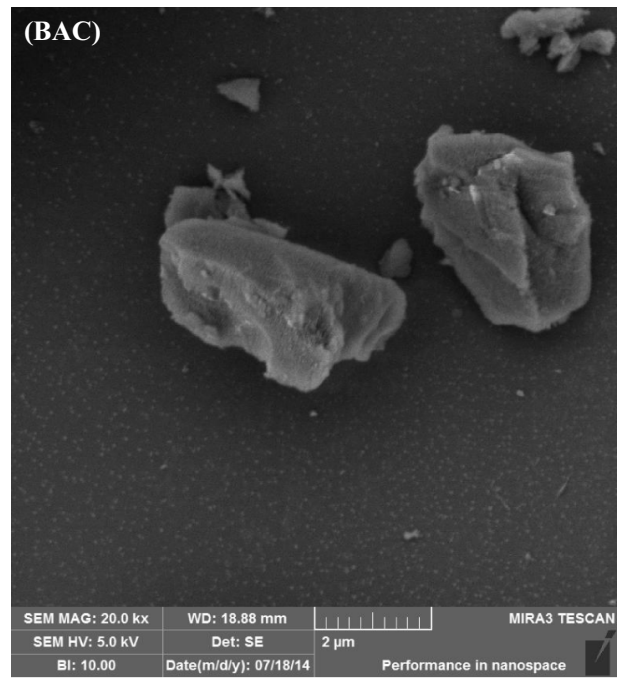

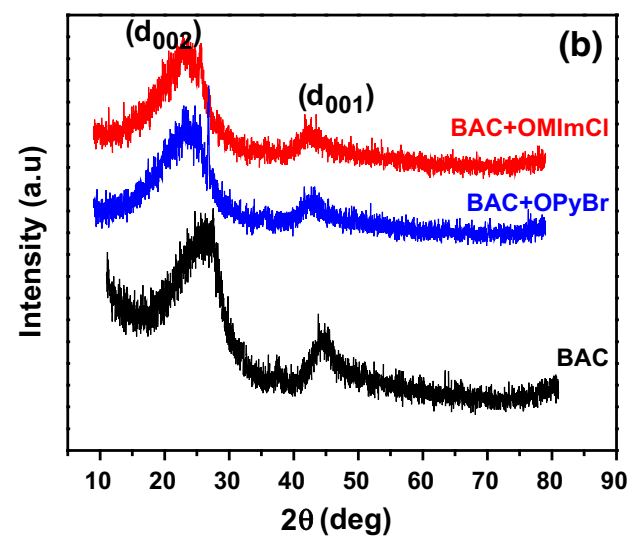

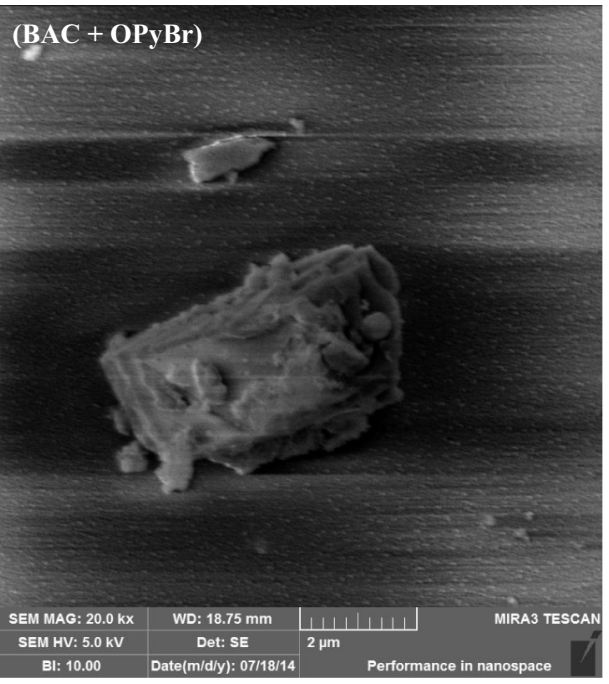

$2,925 \mathrm{~cm}^{-1}$ expresses the $\mathrm{C}-\mathrm{H}$ stretching vibrations (symmetric and asymmetric) of aliphatic $\mathrm{CH}, \mathrm{CH}_{2}$ and $\mathrm{CH}_{3}$ groups. The peak at $1,718 \mathrm{~cm}^{-1}$ was characteristic stretching vibrations of carbonyl group $\mathrm{C}=\mathrm{O}$, and the peak around $1,640 \mathrm{~cm}^{-1}$ corresponds to carbon materials, probably express to carbonyl groups that were conjugated with carbon graphene layer such as quinone (Jiang et al. 2003). The peak at $1,455 \mathrm{~cm}^{-1}$ can be ascribed to $\mathrm{C}-\mathrm{H}$ bending vibrations (Moreno-Castilla et al. 2000). The strong peak at $1,565 \mathrm{~cm}^{-1}$ and a weak peak at $1,413 \mathrm{~cm}^{-1}$ may be due to asymmetric COO- and symmetric $\mathrm{COO}-$ vibrations, respectively (Jiang et al. 2003). Small peak at
$1,370 \mathrm{~cm}^{-1}$ expresses the aromatic $\mathrm{C}=\mathrm{C}$ group, and the $1,150 \mathrm{~cm}^{-1}$ peak corresponds both $\mathrm{O}-\mathrm{H}$ bending modes and $\mathrm{C}-\mathrm{O}$ stretching in carboxylic and phenolic groups (Biniak et al. 1997).

After adsorption of ILs on BAC, a reduction in peaks height, change in peak position and disappearance of some peaks were observed in IR spectrum. The following peaks at $3,420,2,165,1,565$ and $1,370 \mathrm{~cm}^{-1}$ were slightly shifted to the positions at $3,415,2,129,1,550$ and $1,365 \mathrm{~cm}^{-1}$, respectively, and some of these were reduced in height (e.g., 2,129 and 1,365 $\mathrm{cm}^{-1}$ ). Some new peaks were appeared after adsorption of IL on BAC: Peaks at 1,668 
Fig. 2 Kinetic curve of experimental data (a), first-order model (b), second-order model (c) and Boyd model (d) for the adsorption of $\mathrm{BMImCl}$ on $\mathrm{RAC}$ (filled square), AAC (filled circle) and BAC (filled triangle) (initial concentration $1 \mathrm{mmol} / \mathrm{l}$, temperature $25{ }^{\circ} \mathrm{C}$ and $\mathrm{pH} 7$ )
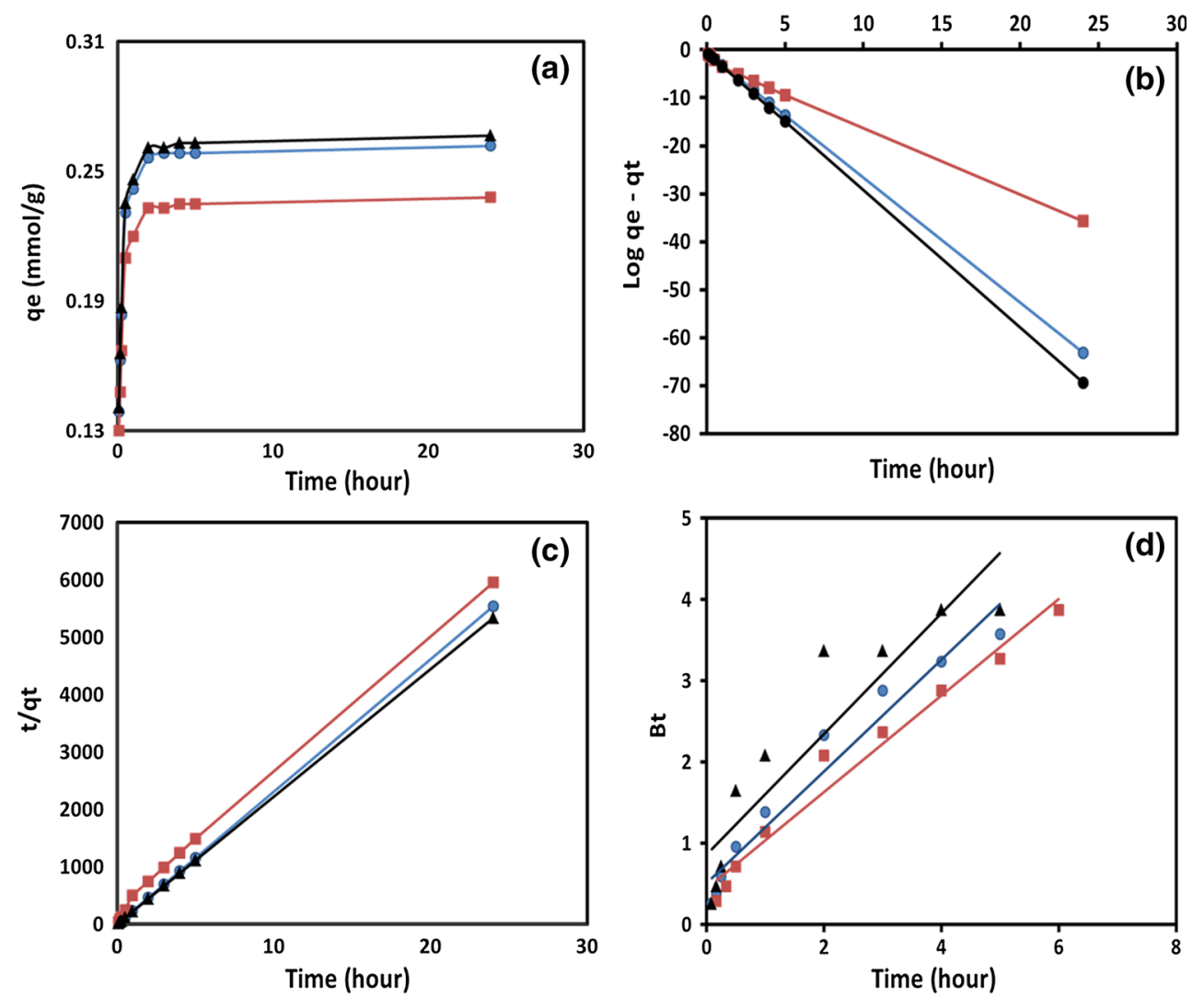

and $1,550 \mathrm{~cm}^{-1}$ region may express the presence of ionradical structures with surface oxygen molecules (Biniak et al. 1999). Another new adsorption peak at $1,330 \mathrm{~cm}^{-1}$ also corresponds to adsorption of IL with oxygen-containing surface functional groups of BAC. These results suggest that oxygen-containing functional groups of ACs are responsible for the adsorption of ionic liquids.

Many researchers have worked on X-ray diffraction analysis of ACs and revealed that AC was an amorphous solid having large pore volume and large internal surface area (Ip et al. 2008; Mohamed et al. 2010; Hanumantharao et al. 2012). It has disordered microcrystalline structure in which graphitic microcrystals of AC were randomly oriented (Mohamed et al. 2010). The XRD of BAC before and after adsorption of ILs is carried out and shown in Fig. 1b. The XRD patterns of BAC show a two typical peak of amorphous $\mathrm{AC}$ at $2 \theta-25.8^{\circ}$ and $2 \theta-50.5^{\circ}$. The XRD pattern of BAC after adsorption of ILs shows a significant change in intensity of these peaks. The peak intensity of $\mathrm{BAC}$ at 50.5 was $120 \mathrm{cps}$, which was reduced to $100 \mathrm{cps}$. This decrease was attributed to the adsorption of ILs on the BAC, which disturbed the crystallinity (Hanumantharao et al. 2012). These observations corroborated well with batch sorption experiments (Hanumantharao et al. 2012).

The scanning electron microscope (SEM) provides the evidence about the surface morphology of the sample. The
SEM images of before and after adsorption of IL onto BAC are shown in Fig. 1c. This figure shows the smooth surface of AC, but after adsorption, the surface was wholly occupied with the molecules of IL which made it rough. These variations in image structure concluded that the IL strongly adsorbed on the surface of the BAC, which also supports the results obtained in BET for the adsorbed AC.

Adsorption study

\section{Adsorption kinetics}

To study the adsorption kinetics of ILs on ACs, $1 \mathrm{mmol} / \mathrm{l}$ initial concentrations of corresponding IL solutions were used. At the beginning, the adsorption of ILs on AC was found to be rapid ( $\sim 30 \mathrm{~min})$, and then, with the increase in contact time $(\sim 1$ to $\sim 24 \mathrm{~h}$ ), it becomes slow and stagnated. After approximately $24 \mathrm{~h}$ of contact time, a plateau was obtained as shown in Fig. 2a.

Generally, the ILs removal rate was rapid initially, but with time it gradually decreased until equilibrium obtained. This phenomenon was attributed to the fact that at initial stage, a large number of vacant adsorption sites were available for adsorption, and after some time, it becomes difficult for solute molecule to occupy the reaming vacant spaces because of repulsion between solute molecule in 
Table 3 Results of the kinetics fitting for the adsorption of three activated fitted by kinetic models on the experimental data obtained at different time intervals

\begin{tabular}{|c|c|c|c|c|c|c|c|c|c|}
\hline \multirow[t]{2}{*}{ Models } & \multicolumn{3}{|l|}{ Raw AC } & \multicolumn{3}{|l|}{$\mathrm{AAC}$} & \multicolumn{3}{|l|}{ BAC } \\
\hline & $k\left(\min ^{-1}\right)$ & $q_{\mathrm{e}}\left(\mathrm{mmol} \mathrm{g}^{-1}\right)$ & $R^{2}$ & $k\left(\min ^{-1}\right)$ & $q_{\mathrm{e}}\left(\mathrm{mmol} . \mathrm{g}^{-1}\right)$ & $R^{2}$ & $k\left(\min ^{-1}\right)$ & $q_{\mathrm{e}}\left(\mathrm{mmol} \mathrm{g}^{-1}\right)$ & $R^{2}$ \\
\hline Pseudo-first-order & 0.06 & 0.23 & 0.97 & 0.12 & 0.25 & 0.97 & 0.10 & 0.25 & 0.97 \\
\hline Pseudo-second-order & 0.38 & 0.24 & 0.99 & 0.70 & 0.26 & 0.99 & 0.68 & 0.26 & 0.99 \\
\hline Elovich's model & 0.86 & 40.34 & 0.95 & 4.87 & 42.59 & 0.94 & 4.87 & 41.80 & 0.94 \\
\hline
\end{tabular}

bulk and on the solid (Ghaedi et al. 2011; Apul et al. 2012; Roosta et al. 2014a). For practical applications, contact time was one of the major parameters. It was found that the AC shows much higher adsorption rate than that of other adsorbents (Crini 2006). This may be its desirable microporous structure, $\pi-\pi$ stacking interaction effect (Dogan et al. 2009) or electrostatic attraction (Ai et al. 2011), particularly for adsorption of the compatible molecule of IL with aromatic ring (Ghaedi et al. 2014).

Different models were applied on the kinetic data in order to understand the characteristics of the adsorption process, but the pseudo-first-order and pseudo-secondorder kinetic models were better to fit to the experimental kinetic data as shown in Fig. 2 (b \& c), respectively. The determination coefficients $\left(R^{2}\right)$ and the obtained kinetic parameters of kinetic models are shown in Table 3. The $R^{2}$ values of the pseudo-second-order kinetic model (0.99) and the experimental values $\left(q_{\mathrm{e}}\right)$ were close to the calculated $\left(q_{e}\right)$, and hence, this model was more appropriate to explain the adsorption behavior of ILs onto ACs, which express that adsorption involves mass transfer of a solute from liquid phase to the adsorbent surface, it is a physicochemical process.

In porous solids, if the movement of adsorbate to the liquid film surrounding the adsorbent was ignored, then the adsorption process might be separated into three stages as follows: (1) film diffusion (outer diffusion or boundary layer diffusion) in which adsorbate was diffused from the liquid film to the exterior surface of adsorbent; (2) intraparticle diffusion (or inner diffusion) in which adsorbate was transported from the exterior surface of adsorbent to the internal structure (pores or capillaries); and (3) the adsorbate was adsorbed onto the active sites of adsorbent (in outer pores surfaces and inner pores surface) (Rengaraj et al. 2004). The third step cannot be treated as rate-limiting step because it was considered to be very fast. Generally, the inner and outer diffusion or both control the adsorption rate. So, we applied the Boyd model, to find out the actual rate-controlling step involved in the ILs sorption process. The plotted $B_{t}$ against time $t$ is shown in Fig. $2 \mathrm{~d}$. The linearity of the plots provides useful information to distinguish between intraparticle diffusion and external mass transfer controlled mechanism of adsorption (Sankar et al. 1999). The plots were linear but not pass through the origin, confirming that in adsorption process, the involvement of external mass transfer was taking place (Gupta et al. 2008).

\section{Adsorption isotherms}

The adsorption equilibrium characteristics were analyzed using the Langmuir-Freundlich, Freundlich, Langmuir and Redlich-Peterson isotherm models, but the Langmuir model was best fitted to the experimental data. The estimated Langmuir model parameters are reported in Table 4.

Figure 3a-c shows the effect of surface chemistry of three ACs on adsorption of all ILs at pH 2, 7 and 9 at room temperature. This figure shows that adsorption of ILs on modified ACs was higher compared to raw AC. The adsorption of OMImCl on BAC, AAC and RAC was 0.94, 0.92 and $0.90 \mathrm{mmol} / \mathrm{g}$, respectively. The same behavior was observed in other two ILs on ACs. The adsorption of ILs on the mACs was higher which suggests that there was a strong interaction between ILs and ACs and the plateau at high concentration showed strong adsorption sites on the adsorbents surface. These results shows that the modified ACs show more ILs adsorption as compared to raw AC. This was because of more functional groups on the surface of modified ACs.

\section{Effect of IL type}

Figure $4 \mathrm{a}$ shows the effect of chain length on the adsorption of ILs on ACs at $\mathrm{pH}$ 9. Generally, OMImCl $(1.16 \mathrm{mmol} / \mathrm{g})$ and $\mathrm{OPyBr}(1.08 \mathrm{mmol} / \mathrm{g})$ show higher adsorption uptake onto ACs compared to $\mathrm{BMImCl}$ $(0.62 \mathrm{mmol} / \mathrm{g})$. This might be explained as: The chain length of $\mathrm{BMImCl}$ was smaller which decreases its hydrophobicity, and the hydrophobic-hydrophobic interactions between AC and IL could be the main force of attraction for adsorption. This behavior of adsorption was also reported in literature before (Farooq et al. 2012). This 
Table 4 Adsorption parameters for various ILs obtained using Langmuir isotherms on the RAC, AAC and BAC obtained by fitting on experimental data

\begin{tabular}{|c|c|c|c|c|c|c|c|c|c|c|c|c|c|}
\hline \multirow[t]{2}{*}{$\mathrm{ACs}$} & \multicolumn{5}{|c|}{$\mathrm{BMImCl}$} & \multicolumn{4}{|c|}{$\mathrm{OMImCl}$} & \multicolumn{4}{|c|}{$\mathrm{OPyBr}$} \\
\hline & $\mathrm{pH}$ & $q_{\mathrm{e}}$ & $b$ & $q_{\max }$ & $R^{2}$ & $q_{\mathrm{e}}$ & $b$ & $q_{\max }$ & $R^{2}$ & $q_{\mathrm{e}}$ & $b$ & $q_{\max }$ & $R^{2}$ \\
\hline \multirow[t]{3}{*}{ RAC } & 2 & 0.42 & 0.44 & 0.43 & 0.99 & 0.90 & 2.02 & 0.90 & 0.99 & 0.87 & 3.01 & 0.90 & 0.99 \\
\hline & 7 & 0.45 & 0.25 & 0.46 & 0.99 & 0.92 & 1.63 & 0.95 & 0.99 & 0.90 & 2.80 & 0.92 & 0.99 \\
\hline & 9 & 0.53 & 0.66 & 0.54 & 0.99 & 0.99 & 3.07 & 0.98 & 0.99 & 0.97 & 3.13 & 0.98 & 0.99 \\
\hline \multirow[t]{3}{*}{$\mathrm{AAC}$} & 2 & 0.45 & 0.43 & 0.48 & 0.99 & 0.92 & 2.55 & 0.92 & 0.99 & 0.90 & 3.52 & 0.91 & 0.99 \\
\hline & 7 & 0.46 & 0.36 & 0.48 & 0.99 & 0.93 & 2.98 & 0.93 & 0.99 & 0.91 & 4.10 & 0.94 & 0.99 \\
\hline & 9 & 0.60 & 1.35 & 0.60 & 0.99 & 1.1 & 5.54 & 1.09 & 0.99 & 1.04 & 5.22 & 1.02 & 0.99 \\
\hline \multirow[t]{3}{*}{ BAC } & 2 & 0.50 & 1.2 & 0.50 & 2 & 0.94 & 3.9 & 0.94 & 2 & 0.91 & 10.1 & 0.96 & 0.99 \\
\hline & 7 & 0.52 & 1.7 & 0.52 & 7 & 1.12 & 8.2 & 1.08 & 7 & 0.98 & 29.5 & 0.98 & 0.99 \\
\hline & 9 & 0.60 & 2.2 & 0.60 & 9 & 1.16 & 19.6 & 1.16 & 9 & 1.04 & 30.5 & 1.04 & 0.99 \\
\hline
\end{tabular}
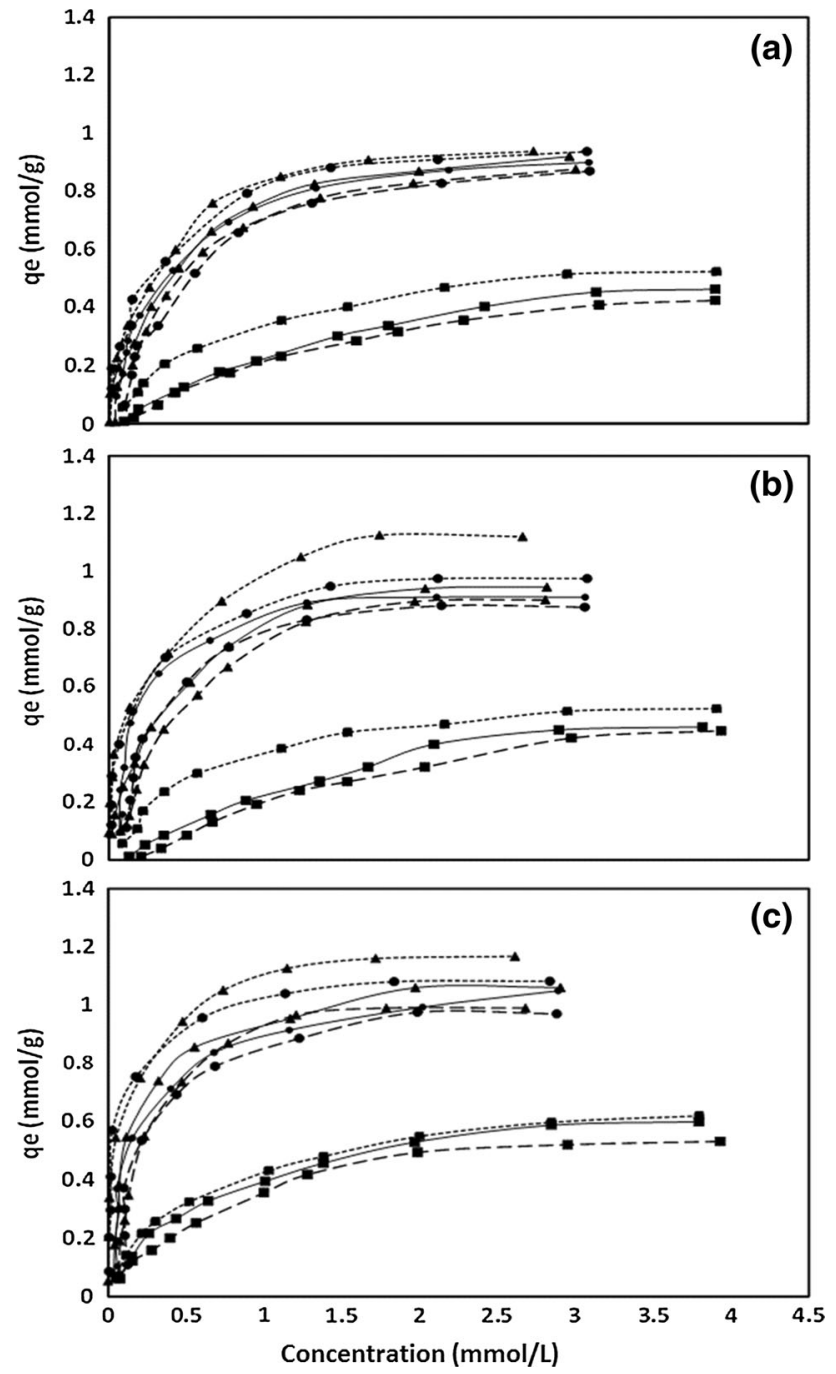

Fig. 3 Adsorption of $\mathrm{BMImCl}$ (filled square), $\mathrm{OPyBr}$ (filled circle) and $\mathrm{OMImCl}$ (filled triangle) onto raw $\mathrm{AC}$ (dashed line), AAC (solid line) and $\mathrm{BAC}$ (dotted line) at $\mathrm{pH}=2(\mathbf{a}), \mathrm{pH} 7(\mathbf{b})$ and $\mathrm{pH} 9$ (c)
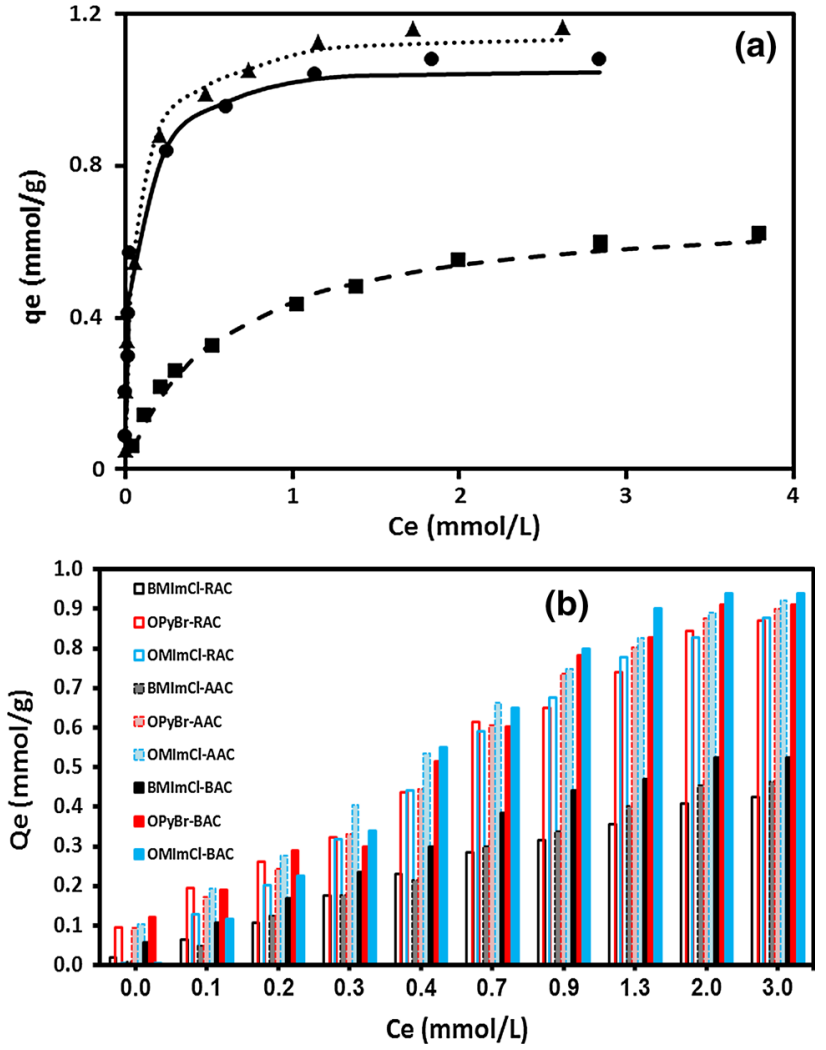

Fig. 4 a Equilibrium adsorption isotherm fitted by Langmuir model of $\mathrm{OMImCl}$ (filled triangle), $\mathrm{OPYBr}$ (filled circle) and $\mathrm{BMImCl}$ (filled square) onto BAC at $\mathrm{pH} 9$ and $\mathbf{b}$ adsorption of all ILs on BAC at $\mathrm{pH} 9$ (filled blocks), $\mathrm{pH} 7$ (dotted blocks) and $\mathrm{pH} 2$ (blank block)

means the adsorption of $\mathrm{BMImCl}$ onto $\mathrm{ACs}$ was expected mainly by the electrostatic interactions, one then the dispersive ones (originating from $\pi-\pi$, hydrophobe-hydrophobe interaction, etc.). Type of isotherms according to Giles classification (Giles et al. 1974) was ' $L$ ' type for the adsorption of ILs onto ACs. 


\section{Effect of $\mathrm{pH}$ on adsorption}

Surface chemistry of ACs (with specific oxygen-containing functional groups) plays an important role in the evolution of adsorption isotherms at various $\mathrm{pH}$ ranges (2-9) shown in Fig. 4b. This figure shows that adsorption of ILs onto $\mathrm{ACs}$ at $\mathrm{pH} 9$ was higher compared to $\mathrm{pH} 2$. The surface of ACs tends to be positively charged at $\mathrm{pH} 2$, while they were negatively charged at $\mathrm{pH} 9$, because at the lower solution $\mathrm{pH}$, the $\mathrm{pH}_{\mathrm{PZC}}$ of the ACs was higher compared to solution $\mathrm{pH}$, and at higher solution $\mathrm{pH}$, the $\mathrm{pH}_{\mathrm{PZC}}$ of the ACs was lower compared to solution $\mathrm{pH}$, and the value of $\mathrm{pH}_{\mathrm{PZC}}$ is shown in Table 1 . The AC which contains maximum amount of surface oxygen groups shows lower $\mathrm{pH}_{\mathrm{PZC}}$. Among the studied ACs, mAC contains the higher amount of oxygen groups compared to raw AC, and thus, they possess the lower $\mathrm{pH}_{\mathrm{PZC}}$ value and hence show higher adsorption for ILs.

This effect of $\mathrm{pH}$ on adsorption suggests that there were two kinds of forces exist between ILs and ACs surface: electrostatic interactions (where the carbon surface becomes negatively charged), which were predominant at basic $\mathrm{pH}(\mathrm{pH}=9)$, and dispersive Interactions at $\mathrm{pH}=2$.

Figure $4 \mathrm{~b}$ shows that the amount of oxygen groups on the surface of mAC (i.e., their acidity) significantly effects on their maximum adsorption value (at $\mathrm{pH} 2$ and 9). Because at $\mathrm{pH} \mathrm{9,} \mathrm{the} \mathrm{strength} \mathrm{of} \mathrm{electrostatic} \mathrm{interaction}$ was increased due to increase in negative charges on the surface of AC (adsorption uptake increases with decease of $\mathrm{pH}_{\mathrm{PZC}}$ value), and at $\mathrm{pH} \mathrm{2,} \mathrm{only} \mathrm{dispersive} \mathrm{forces} \mathrm{exist,}$ which decreased adsorption uptake of ACs for ILs.

The cations size of IL was compatible with the AC micropores volume, i.e., due to the lower size of IL cations, the micropore volume of $\mathrm{AC}$ was accessible (molecules length of IL $<1.5 \mathrm{~nm}$ ). In fact, the thickness of all molecules was very small $(<0.2 \mathrm{~nm})$, which could adsorb even into the smaller slit pores, i.e., ultramicropores. The knees at low adsorption on the isotherms (Fig. 4) were in agreement with the ultramicropores content in the carbons. This suggests that adsorption sites were mainly the small micropores. The same trend was found in work of Farooq et al. (2012).

Moreover, the $\mathrm{R}_{\mathrm{L}}$ value of $\mathrm{BAC}$ was 0.01 for OMImCl, 0.08 for $\mathrm{BMImCl}$ and 0.006 for $\mathrm{OPyBr}$ at $\mathrm{pH} 9$; similar trend found in other $\mathrm{AC}$ (not shown here) indicating that the adsorption of ILs onto ACs was more favorable at higher $\mathrm{pH}$, and the $\mathrm{mAC}$ was a good adsorbent material for ILs removal from aqueous solution.

Figure 5 shows the difference between maximum adsorption uptake values at $\mathrm{pH} 2$ and 9, which was

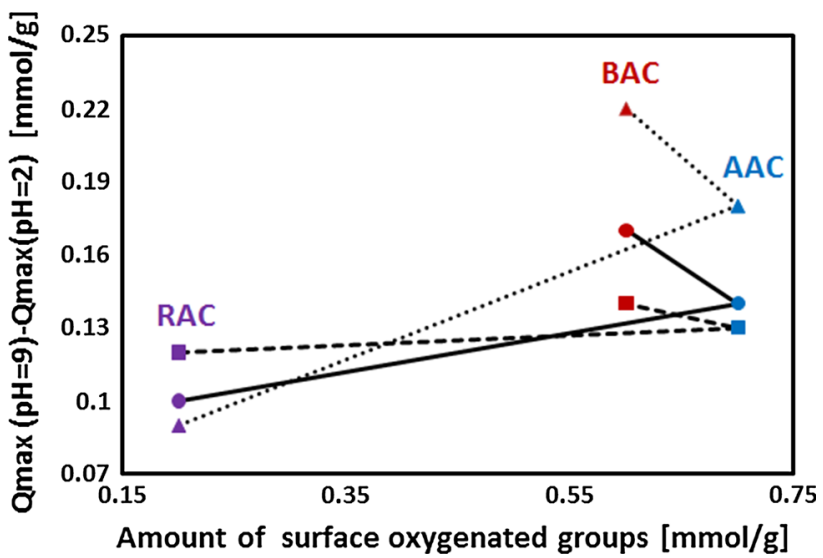

Fig. 5 Difference between maximum adsorption uptakes $\left(Q_{\max }\right)$ for $\mathrm{BMImCl}$ (filled square), $\mathrm{OPyBr}$ (filled circle) and $\mathrm{OMImCl}$ (filled triangle) measured at $\mathrm{pH}=9$ and 2 as a function of the oxygen content of activated carbons

Table 5 Comparison of present results with published one on adsorption of ILs using ACs

\begin{tabular}{|c|c|c|c|}
\hline AC type & ILs & $\begin{array}{l}q_{\max } \\
(\mathrm{mmol} / \mathrm{g})\end{array}$ & Reference \\
\hline Activated carbon & {$\left[\mathrm{C}_{4} \mathrm{C}_{1} \mathrm{im}\right] \mathrm{Cl}$} & 0.26 & $\begin{array}{l}\text { Neves et al. } \\
\text { (2014) }\end{array}$ \\
\hline MKU- $\mathrm{HNO}_{3}$ & $\mathrm{BMImCl}$ & 0.24 & $\begin{array}{l}\text { Lemus et al. } \\
\text { (2012) }\end{array}$ \\
\hline CAPSUPER- $\mathrm{HNO}_{3}$ & $\mathrm{BMImCl}$ & 0.90 & $\begin{array}{l}\text { Lemus et al. } \\
\text { (2012) }\end{array}$ \\
\hline \multirow[t]{2}{*}{ AC-MKU } & $\mathrm{OMImCl}$ & 0.65 & \multirow{2}{*}{$\begin{array}{l}\text { Palomar et al. } \\
\text { (2009a) }\end{array}$} \\
\hline & $\mathrm{BMImCl}$ & 0.52 & \\
\hline \multirow{3}{*}{$\begin{array}{l}\text { Granulated Chinese } \\
\mathrm{AC} \text { at } \mathrm{pH} 9\end{array}$} & $\mathrm{BMImCl}$ & 0.45 & \multirow{3}{*}{$\begin{array}{l}\text { Farooq et al. } \\
\text { (2012) }\end{array}$} \\
\hline & $\mathrm{OMImCl}$ & 1.45 & \\
\hline & $\mathrm{OPyBr}$ & 0.65 & \\
\hline \multirow[t]{3}{*}{ BAC } & $\mathrm{BMImCl}$ & 0.60 & \multirow[t]{3}{*}{ Present work } \\
\hline & $\mathrm{OMImCl}$ & 1.16 & \\
\hline & OPyBr & 1.04 & \\
\hline
\end{tabular}

proportional to the number of surface oxygenated groups on respective AC. This trend was due to the presence of oxygen-containing groups on the surface of AC. These oxygen groups increase the strength of electrostatic force of interaction at $\mathrm{pH}=9$. The value of subtraction between the adsorption uptake at $\mathrm{pH} 9$ and 2 expressed the following trend $\mathrm{OMImCl}<\mathrm{OPyBr}<\mathrm{BMImCl}$ for all three studied ACs. This trend shows that the IL cations on ACs tend to be adsorbed through weaker dispersive interactions and stronger electrostatic interactions, which confirms the 
profile of adsorption isotherms at various $\mathrm{pH}$ for the three ILs on three ACs.

Palomar et al. (2009b) have also tailored the surface of activated carbon and showed that the adsorption of $\mathrm{OMImPF}_{6}$ (1-methyl-3-octylimidazolium hexafluorophosphate) increases with increase in the oxygen content on the surface of activated carbon. Hence, it was also clear from this study that with the increase in surface oxygen groups of AC, electrostatic attractions with adsorbate were enhanced.

As the textural properties of the adsorbents did not change, the difference in ionic liquid uptakes for the raw AC and modified ACs may explain the difference in chemical nature of surface modified ACs from that of raw AC.

\section{Literature comparison}

The maximum adsorption capacity $\left(q_{\mathrm{max}}\right)$ of ILs obtained from isotherm model is compared with literature $q_{\max }$ values of other adsorbents used for adsorption of IL. This comparison is depicted in Table 5. The $q_{\max }$ results obtained in this study showed comparably higher value with published literature.

\section{Conclusion}

Granulated AC was modified successfully with $\mathrm{HNO}_{3}$ and $\mathrm{NaOCl}$. Modified ACs contained oxygenated surface groups: carboxylic acid, lection, phenolic and basic groups.

The mACs were demonstrated as an efficient adsorbent material for the removal of ILs in aqueous solutions, which can be attributed to multiple adsorption interaction mechanisms (e.g., $\pi-\pi$ interactions hydrogen bonding, electrostatic interactions, mesopore filling, etc.) between ILs and ACs. BET results showed that surface of modified ACs was altered with decreasing micropore volume, but the textural properties remain same. Boehm titration results showed that surface of AAC and BAC contains carboxylic, lactones, phenol and basic groups. Adsorption study of ILs on ACs showed that IL of higher chain showed higher adsorption and adsorption increased at $\mathrm{pH} 9$ than $\mathrm{pH} 2$, as surface of AC got positive at higher $\mathrm{pH}$. In modified ACs, BAC showed higher adsorption compared to AAC. Kinetic data were successfully fitted by pseudo-first-order and pseudo-second-order models, and isotherm data were best fitted by Langmuir model. The BET study of ILs adsorbed on ACs showed that considerable adsorption of ILs took place. The $\mathrm{q}_{\max }$ results obtained in this study showed comparably higher value with published literature. This finding indicated that oxidation of $\mathrm{AC}$ could be a useful method to improve the adsorption affinity of ILs. Therefore, the AC may be a promising adsorbent for organic pollutants in aqueous solutions.

Acknowledgments One of the authors Safia Hassan is highly obliged to Higher Education Commission of Pakistan for granting her research scholarship.

\section{References}

Ai L, Zhang C, Liao F, Wang Y, Li M, Meng L, Meng L, Jiang J (2011) Removal of methylene blue from aqueous solution with magnetite loaded multi-wall carbon nanotube: kinetic, isotherm and mechanism analysis. J Hazard Mater 198:282-290

Apul OG, Shao T, Zhang S, Karanfil T (2012) Impact of carbon nanotube morphology on phenanthrene adsorption. Environ Toxicol Chem 31:73-78

Armand M, Endres F, MacFarlane DR, Ohno H, Scrosati B (2009) Ionic-liquid materials for the electrochemical challenges of the future. Nature Mater 8:621-629

Biniak S, Szymański G, Siedlewski J, Swiatkowski A (1997) The characterization of activated carbons with oxygen and nitrogen surface groups. Carbon 35:1799-1810

Biniak S, Pakula M, Szymanski GS, Swiatkowski A (1999) Effect of activated carbon surface oxygen-and/or nitrogen-containing groups on adsorption of copper (II) ions from aqueous solution. Langmuir 15:6117-6122

Boehm HP (1994) Some aspects of the surface chemistry of carbon blacks and other carbons. Carbon 32:759-769

Chien SH, Clayton WR (1980) Application of Elovich equation to the kinetics of phosphate release and sorption in soils. Soil Sci Soc Am J 44:265-268

Claudio AFM, Freire MG, Freire CS, Silvestre AJ, Coutinho JA (2010) Extraction of vanillin using ionic-liquid-based aqueous two-phase systems. Sep Purif Technol 75:39-47

Conway BE (1999) Electrochemical supercapacitors: scientific fundamentals and technological applications. Plenum Press, New York

Crini G (2006) Non-conventional low-cost adsorbents for dye removal: a review. Bioresource Technol 97:1061-1085

Dogan M, Abak H, Alkan M (2009) Adsorption of methylene blue onto hazelnut shell: kinetics, mechanism and activation parameters. J Hazard Mater 164:172-181

Donnet JB, Bansal RC (1990) Carbon fibers, 2nd edn. Wiley Online Library, New York Marcel Dekker

Donnet J, Ehrburger P (1977) Carbon fibre in polymer reinforcement. Carbon 15:143-152

Ermolenko IN, Lyubliner I, Gulko NV (1990) Chemically modified carbon fibers and their applications. VCH Weinheim, Germany

Faria PCC, Orfao JJM, Pereira MFR (2004) Adsorption of anionic and cationic dyes on activated carbons with different surface chemistries. Water Res 38:2043-2052

Farooq A, Reinert L, Leveque J-M, Papaiconomou N, Irfan N, Duclaux L (2012) Adsorption of ionic liquids onto activated carbons: effect of $\mathrm{pH}$ and temperature. Micropor Mesopor Mat 158:55-63 
Figueiredo JL, Pereira MFR, Freitas MMA, Orfao JJM (1999) Modification of the surface chemistry of activated carbons. Carbon 37:1379-1389

Franz M, Arafat HA, Pinto NG (2000) Effect of chemical surface heterogeneity on the adsorption mechanism of dissolved aromatics on activated carbon. Carbon 38:1807-1819

Ghaedi M, Hassanzadeh A, Kokhdan SN (2011) Multiwalled carbon nanotubes as adsorbents for the kinetic and equilibrium study of the removal of Alizarin Red S and Morin. J Chem Eng Data 56:2511-2520

Ghaedi M, Ansari A, Habibi M, Asghari A (2014) Removal of malachite green from aqueous solution by zinc oxide nanoparticle loaded on activated carbon: kinetics and isotherm study. J Ind Eng Chem 20:17-28

Giles CH, Smith D, Huitson A (1974) A general treatment and classification of the solute adsorption isotherm. I. Theoretical. J Colloid Interf Sci 47:755-765

Gupta VK, Mittal A, Gajbe V, Mittal J (2008) Adsorption of basic fuchsin using waste materials-bottom ash and deoiled soya-as adsorbents. J Colloid Interf Sci 319:30-39

Han X, Armstrong DW (2007) Ionic liquids in separations. Acc Chem Res 40:1079-1086

Hanumantharao Y, Kishore M, Ravindhranath K (2012) Characterization and defluoridation studies of active carbon derived from typha angustata plants. J Adhes Sci Technol 3:167-181

Ho YS, McKay G (1998) Sorption of dye from aqueous solution by peat. Chem Eng J 70:115-124

Ho Y-S, McKay G (1999) Pseudo-second order model for sorption processes. Process Biochem 34:451-465

Ip A, Barford J, McKay G (2008) Production and comparison of high surface area bamboo derived active carbons. Bioresource Technol 99:8909-8916

Jiang Z, Liu Y, Sun X, Tian F, Sun F, Liang C et al (2003) Activated carbons chemically modified by concentrated $\mathrm{H}_{2} \mathrm{SO}_{4}$ for the adsorption of the pollutants from wastewater and the dibenzothiophene from fuel oils. Langmuir 19:731-736

Kumar KV, Ramamurthi V, Sivanesan S (2005) Modeling the mechanism involved during the sorption of methylene blue onto fly ash. J Colloid Interf Sci 284:14-21

Kutics K, Suzuki M (1990) Adsorption of organics on surface modified activated carbon fibers. In: The 2nd Korea-Japan symposium on separation technology, Korea-Japan, pp 1-2

Lemus J, Palomar J, Heras F, Gilarranz MA, Rodriguez JJ (2012) Developing criteria for the recovery of ionic liquids from aqueous phase by adsorption with activated carbon. Sep Purif Technol 97:11-19

Lisovskii A, Semiat R, Aharoni C (1997) Adsorption of sulfur dioxide by active carbon treated by nitric acid: I. effect of the treatment on adsorption of $\mathrm{SO}_{2}$ and extractability of the acid formed. Carbon 35:1639-1643

Lopez-Ramon M, Stoeckli F, Moreno-Castilla C, Carrasco-Marin F (1999) On the characterization of acidic and basic surface sites on carbons by various techniques. Carbon 37:1215-1221

Mattson JA, Mark HB, Malbin MD, Weber WJ, Crittenden JC (1969) Surface chemistry of active carbon: specific adsorption of phenols. J Colloid Interf Sci 31:116-130

Migowski P, Dupont J (2007) Catalytic applications of metal nanoparticles in imidazolium ionic liquids. Chem Eur J 13:32-39

Mohamed AR, Mohammadi M, Darzi GN (2010) Preparation of carbon molecular sieve from lignocellulosic biomass: a review. Renew Sust Energ Rev 14:1591-1599

Moreno-Castilla C, Carrasco-Marin F, Maldonado-Hodar FJ, RiveraUtrilla J (1998) Effects of non-oxidant and oxidant acid treatments on the surface properties of an activated carbon with very low ash content. Carbon 36:145-151
Moreno-Castilla C, Lopez-Ramon M, Carrasco-Marın F (2000) Changes in surface chemistry of activated carbons by wet oxidation. Carbon 38:1995-2001

Neves CM, Lemus J, Freire MG, Palomar J, Coutinho JA (2014) Enhancing the adsorption of ionic liquids onto activated carbon by the addition of inorganic salts. Chem Eng J 252:305-310

Olivier-Bourbigou H, Magna L, Morvan D (2010) Ionic liquids and catalysis: recent progress from knowledge to applications. Appl Catal A-Gen 373:1-56

Palomar J, Lemus J, Gilarranz M, Rodriguez J (2009a) Adsorption of ionic liquids from aqueous effluents by activated carbon. Carbon 47:1846-1856

Palomar J, Lemus J, Gilarranz MA, Rodriguez JJ (2009b) Adsorption of ionic liquids from aqueous effluents by activated carbon. Carbon 47:1846-1856

Park S-J, Kim M-H (2000) Effect of acidic anode treatment on carbon fibers for increasing fiber-matrix adhesion and its relationship to interlaminar shear strength of composites. J Mater Sci 35:1901-1905

Peebles LH (1995) Formation, structure, and properties. In: Carbon fibers. CRC Press, Boca Raton, FL

Pittman CU, He GR, Wu B, Gardner SD (1997) Chemical modification of carbon fiber surfaces by nitric acid oxidation followed by reaction with tetraethylenepentamine. Carbon 35:317-331

Plechkova NV, Seddon KR (2008) Applications of ionic liquids in the chemical industry. Chem Soc Rev 37:123-150

Radovic LR, Silva IF, Ume JI, MenÃ@ $@$ ndez JA, Leon CALY, Scaroni AW (1997) An experimental and theoretical study of the adsorption of aromatics possessing electron-withdrawing and electron-donating functional groups by chemically modified activated carbons. Carbon 35:1339-1348

Rengaraj S, Kim Y, Joo CK, Yi J (2004) Removal of copper from aqueous solution by aminated and protonated mesoporous aluminas: kinetics and equilibrium. J Colloid Interf Sci 273:14-21

Roosta M, Ghaedi M, Daneshfar A, Sahraei R (2014a) Experimental design based response surface methodology optimization of ultrasonic assisted adsorption of safaranin $\mathrm{O}$ by tin sulfide nanoparticle loaded on activated carbon. Spectrochim Acta A 122:223-231

Roosta M, Ghaedi M, Daneshfar A, Sahraei R, Asghari A (2014b) Optimization of the ultrasonic assisted removal of methylene blue by gold nanoparticles loaded on activated carbon using experimental design methodology. Ultrason Sonochem 21:242-252

Roosta M, Ghaedi M, Shokri N, Daneshfar A, Sahraei R, Asghari A (2014c) Optimization of the combined ultrasonic assisted/ adsorption method for the removal of malachite green by gold nanoparticles loaded on activated carbon: experimental design. Spectrochim Acta A 118:55-65

Sankar M, Sekaran G, Sadulla S, Ramasami T (1999) Removal of diazo and triphenylmethane dyes from aqueous solutions through an adsorption process. J Chem Technol Biotechnol 74:337-344

Shim J-W, Park S-J, Ryu S-K (2001) Effect of modification with $\mathrm{HNO}_{3}$ and $\mathrm{NaOH}$ on metal adsorption by pitch-based activated carbon fibers. Carbon 39:1635-1642

Sonawane GH, Shrivastava VS (2011) Orange-II removal from simulated wastewater by adsorption using Annona squamosa shell-A kinetic and equilibrium studies. Desalin Water Treat 36:374-382

van Rantwijk F, Sheldon RA (2007) Biocatalysis in ionic liquids. Chem Rev 107:2757-2785

Wasserscheid P, Welton T (2008) Ionic liquids in synthesis. Wiley. doi:10.1002/9783527621194 
Weast RC (1990) Handbook of chemistry and physics, 70th edn. CRC Press, Boca Raton, Florida

Weber WJ, Morris JC (1963) Kinetics of adsorption on carbon from solution. J Sanit Eng Div Am Soc Civ Eng 89:31-60
Xu B, Wu F, Chen R, Cao G, Chen S, Yang Y (2010) Mesoporous activated carbon fiber as electrode material for high-performance electrochemical double layer capacitors with ionic liquid electrolyte. J Power Sources 195:2118-2124 